\title{
Association between anti-citrullinated alpha enolase antibodies and clinical features in a cohort of patients with rheumatoid arthritis: a pilot study
}

\author{
A. Alunno ${ }^{1}$, O. Bistoni ${ }^{1}$, F. Pratesi ${ }^{2}$, F. Topini' ${ }^{1}$ I. Puxeddu' ${ }^{2}$, V. Valentini', \\ G. Cafaro' ${ }^{1}$, E. Bartoloni', P. Migliorini' ${ }^{2}$, R. Gerli ${ }^{1}$ \\ ${ }^{1}$ Rheumatology Unit, Department of Medicine, University of Perugia, Italy; \\ ${ }^{2}$ Clinical Immunology and Allergy Unit, Department of Clinical and Experimental Medicine, University of Pisa, Italy
}

\section{SUMMARY}

In recent years several antibodies against citrullinated peptides (ACPAs) have been identified in patients with rheumatoid arthritis (RA) and their pathogenic, diagnostic and prognostic significance is under intense investigation. Among ACPAs, those targeting citrullinated alpha enolase (anti-CEP1) have been identified in RA but data about their ability to predict the development of erosive disease are conflicting. Furthermore, no data are currently available concerning their possible association with extra-articular manifestations (EAMs) in RA. The aim of this study was to investigate the prevalence and significance of anti-CEP1 from a prognostic point of view. In this pilot study we confirmed that anti-CEP1 Abs are associated with higher prevalence of bone erosions, but we also provided the first evidence of an association between anti-CEP1 Abs and RA interstitial lung disease (ILD). These results provide the basis to investigate the association between anti-CEP1 Abs and EAMs in larger cohorts of RA patients to possibly confirm its role as biomarker for RA-ILD.

Key words: Rheumatoid arthritis.

Reumatismo, 2018; 70 (2): 67-71

\section{INTRODUCTION}

heumatoid arthritis (RA) is a chronic inflammatory disease characterised by synovitis and leading to bone erosion, joint damage and disability $(1,2)$. In a subgroup of patients, the clinical spectrum is heterogeneous and includes extra-articular manifestations (EAMs) (3). EAMs worsen RA prognosis, since cardiovascular disease and pulmonary involvement are the two most frequent causes of death in RA (4). The identification of predictive biomarkers of erosive disease and EAM development is under intense investigation, but none of them is reliable enough to ensure the exact identification and thorough follow-up of all the patients at higher risk (5). For instance, although rheumatoid factor (RF) and anticyclic citrullinated peptide (anti-CCP) antibodies (Abs) have been clearly linked to a more severe articular disease and a higher risk of EAMs (6), these manifestations can nevertheless be detected also in seronegative patients, suggesting that other biomarkers are needed to identify this subgroup of high risk subjects. In this regard, the field of Abs anti-citrullinated peptides (ACPA) is rapidly expanding with several target antigens identified over the last decade. The diagnostic and prognostic role of different ACPAs in RA is debated and conflicting results have been obtained in different cohorts $(7,8)$. The immunodominant citrullinated alfa-enolase peptide 1 (CEP1) is one of these newly identified targets of ACPA and anti-CEP1 Abs were first described in RA synovial fluid (SF) in 2008 (9) and in RA serum in 2009 (10). According to different studies, serum Anti-CEP1 Abs are detectable in $24-80 \%$ of RA patients (1013) and are associated with genetic fac-
Conference presentation: LIII SIR Congress (2016).
Corresponding author: Roberto Gerli Rheumatology Unit, Department of Medicine University of Perugia, Edificio C, $5^{\circ}$ Piano Piazzale Menghini, 1 06129 S. Andrea delle Fratte (PG), Italy E-mail: roberto.gerli@unipg.it 
tors that increase RA susceptibility such as HLA-DRB1 and PTPN22 (12-14). The association between anti-CEP1 Abs and bone erosions is unclear, as the available studies yield conflicting results $(12,13)$. In addition, no evidence regarding an association between anti-CEP1 and EAMs is available. The aim of our study was to investigate the prevalence of bone erosions and EAMs in RA patients displaying anti-CEP1 compared to anti-CEP-1 negative patients.

\section{MATERIALS AND METHODS}

\section{Patient cohort}

One-hundred patients with RA according to the 1987 American College of Rheumatology Classification criteria (15), referring to the Rheumatology Unit of the University of Perugia and the Clinical Immunology and Allergy Unit of the University of Pisa, were enrolled. Fifty sex- and age-matched healthy donors (HD) acted as controls. Demographic, clinical (including all possible EAMs), radiological and serological records were collected retrospectively through the revision of patient charts. The study was approved by the local Ethical Committee and all enrolled subjects provided written informed consent according to the Declaration of Helsinki.

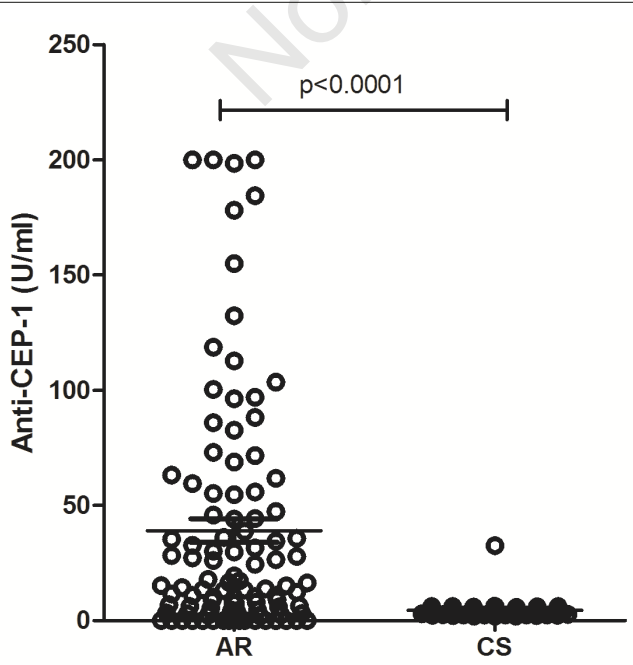

Figure 1 - Distribution of anti-CEP1 antibodies in patients with rheumatoid arthritis (RA) and healthy donors (HD).

\section{Antibody detection}

Anti-CCP IgG antibodies were assessed in serum samples with second generation ELISA kits (EliA - Thermo Scientific). Anti-CEP-1 IgG antibodies were assessed with a commercially available ELISA kit (Euroimmun) according to the manufacturer's instructions.

\section{Statistical analysis}

Data were processed with SPSS 21.0. Chi square test, Mann-Whitney $U$ test and Spearman correlation coefficient were calculated as needed.

\section{RESULTS}

\section{Anti-CEP1 positivity distribution in $R A$ and $H D$}

As depicted in Figure 1, anti-CEP1 antibodies resulted significantly more prevalent in the RA cohort compared to HD. In fact, 45 out of 100 RA patients (45\%) and 1 out of $50 \mathrm{HD}(2 \%)$ displayed these antibodies $(\mathrm{p}<0.0001)$. RA patients also displayed higher antibody titers $(\mathrm{p}<0.0001)$. With regard to the co-existence of anti-CEP1 and anti-CCP Abs, we observed that 38 out of 100 RA patients (38\%) displayed both antiCEP1 and anti-CCP Abs, 28 patients (28\%) displayed neither anti-CEP1 nor anti-CCP Abs, 28 patients (28\%) displayed only anti-CCP Abs and 7 patients (7\%) displayed only anti-CEP1 Abs. In addition anti-CEP1 and anti-CCP titers were strongly correlated (Spearman's rho=0.56, $\mathrm{p}<0.0001)$.

\section{Anti-CEP1 antibodies are associated with erosive disease and ILD}

We subsequently divided patients according to their serological status (both Abs negative, both Abs positive, only one Abs positive). No difference was observed regarding gender, age, age at diagnosis and disease duration. However, a different prevalence of erosive disease and interstitial lung disease (ILD) was detected among the groups (Table I). We did not observe any difference in the prevalence of any other EAM among the 4 groups using the Chisquare test (data not shown). In our cohort, the prevalence of erosive disease and ILD 
was similar in current/former smokers and non-smokers. Interestingly, however, distribution and titer of anti-CEP1 and CCP in smokers/non-smokers with ILD were different. The majority of smokers with ILD $(75 \%)$ displayed either anti-CCP alone or anti-CCP plus anti-CEP-1. Conversely, $80 \%$ of non-smokers with ILD displayed either anti-CEP1 alone or anti-CCP plus anti CEP-1 (Table II).

\section{DISCUSSION AND CONCLUSIONS}

In the last decades, the diagnostic and prognostic roles of ACPA in RA have been extensively investigated (16). As previously reported (12), we confirmed in this pilot study that anti-CEP1 Abs are associated with higher prevalence of bone erosions, but we also provided the first evidence of an association between anti-CEP1 Abs and RA-ILD.

Bone erosions represent a hallmark of RA, being detectable in more than half of RA patients and leading to irreversible joint damage and loss of function (17). Erosions develop as consequence of persistent chronic inflammation through a multistep process. Several cells and soluble mediators belonging to the immune system are involved in this process, including autoAbs, the latter being able to activate osteoclasts either directly or through their Fc (18). In addition, it is known that ACPA may occur years before the diagnosis of RA and that some patients already display erosions at the time of diagnosis. These observations may further strengthen the role of ACPA in the development of bone erosions (1922 ). With regard to the association between anti-CEP1 and ILD, it is interesting to note that $70 \%$ of patients with ILD display either anti-CEP1 alone or in association with anti-CCP, while only a small proportion of anti-CCP+ anti-CEP1- patients display ILD. This evidence is partially in contrast with previous literature reporting a higher

Table I - Demographic and clinical features of patients with rheumatoid arthritis according to the anti-CCP and anti-CEP1 serological status.

\begin{tabular}{|l|c|c|c|c|c|c|}
\hline & All & anti-CCP- anti-CEP1- & anti-CCP+ anti-CEP- & anti-CCP- anti-CEP+ & anti-CCP+ anti-CEP+ & P \\
\hline Patients (number) & 100 & 28 & 28 & 7 & 37 & - \\
\hline Age (years) & $62 \pm 2$ & $63 \pm 2$ & $63 \pm 2$ & $60 \pm 1$ & $61 \pm 2$ & $n s$ \\
\hline $\begin{array}{l}\text { Age at diagnosis } \\
\text { (years) }\end{array}$ & $50 \pm 2$ & $52 \pm 1$ & $52 \pm 2$ & $51 \pm 3$ & $50 \pm 2$ & $\mathrm{~ns}$ \\
\hline $\begin{array}{l}\text { Disease duration } \\
\text { (years) }\end{array}$ & $12 \pm 3$ & $12 \pm 2$ & $13 \pm 1$ & $11 \pm 2$ & $13 \pm 2$ & $\mathrm{~ns}$ \\
\hline $\begin{array}{l}\text { Erosions number } \\
\text { (percentage) }\end{array}$ & $60(60 \%)$ & $10(36 \%)$ & $19(68 \%)$ & $7(100 \%)$ & $25(67 \%)$ & 0.004 \\
\hline $\begin{array}{l}\text { RA-ILD number } \\
\text { (percentage) }\end{array}$ & $21(21 \%)$ & $3(11 \%)$ & $3(11 \%)$ & $5(70 \%)$ & $10(27 \%)$ & 0.002 \\
\hline
\end{tabular}

Table II - Smoking habit and interstitial lung disease prevalence in patients with rheumatoid arthritis the anti-CCP and anti-CEP1 serological status (all values are shown as number (percentage) of patients).

\begin{tabular}{|l|c|c|c|c|}
\hline & anti-CCP- anti-CEP1- & anti-CCP+ anti-CEP- & anti-CCP- anti-CEP+ & anti-CCP+ anti-CEP+ \\
\hline Patients & 28 & 28 & 7 & 37 \\
\hline Non-smokers No ILD & $21(75 \%)$ & $20(72 \%)$ & $0(0 \%)$ & $14(38 \%)$ \\
\hline Non-smokers ILD & $1(3 \%)$ & $2(7 \%)$ & $5(72 \%)$ & $5(13 \%)$ \\
\hline Smokers & $5(18 \%)$ & $5(18 \%)$ & $1(14 \%)$ & $13(36 \%)$ \\
\hline No ILD & $1(3 \%)$ & $1(3 \%)$ & $1(14 \%)$ & $5(13 \%)$ \\
\hline Smokers ILD & \multicolumn{1}{|c|}{} & &
\end{tabular}


prevalence of ILD in anti-CCP+ patients (23). In fact, if we cumulate data from all anti-CCP+ patients independently of antiCEP1, we observe ILD in $20 \%$ of patients. Conversely, if we cumulate data from all anti-CEP+ patients independently of antiCCP1, we observe ILD in $34 \%$ of patients. This clearly demonstrated that, in patients with double positivity, the association with ILD is mainly dependent on anti-CEP1, rather than on anti-CCP. In this regard, it is important to note that previous studies assessed only anti-CCP Abs. Therefore, the contribution of other ACPA subtypes to the association of anti-CCP and ILD cannot be ruled out.

The distribution of autoAbs between smokers and non-smokers in our RA cohort also deserves some consideration. It is now well established that cigarette smoke increases the activity of the peptidyl amino deaminase (PAD) enzyme, which is the mediator of protein citrullination. Furthermore, smoking is strongly associated with the development of ILD. Therefore, smokers are more likely to be seropositive and more often develop RA-ILD $(23,24)$. However, it is conceivable that other mechanisms could be responsible for aberrant peptide citrullination, otherwise the presence of ACPA in non-smokers could not be explained. In our cohort, among smokers and non-smokers with ILD, only one patient per group is negative for both anti-CEP1 and anti-CCP. It is of interest that all patients with ILD who were positive for anti-CEP1, but not anti-CCP, had never smoked. An explanation may be the possible coexistence of a Porphyromonas $(P$.$) gingivalis-induced$ periodontitis, as this bacterium is equipped with the PAD enzyme (25). Furthermore, CEP-1 displays $82 \%$ homology with enolase from $P$. gingivalis, the levels of antiCEP-1 correlate with the levels of Abs to the bacterial peptide (26) and anti-P. gingivalis $\mathrm{Ab}$ titer is higher in RA patients who had never smoked compared to patients who had regularly smoked and among nonsmokers (27). The association between $P$. gingivalis and anti-CEP1 represents an intriguing issue deserving further investigation in the future.
In conclusion, our pilot study provides the basis to investigate the association between anti-CEP1 Abs and EAMs in larger cohorts of RA patients to possibly confirm its role as biomarker for RA-ILD.

\section{REFERENCES}

1. Smolen JS, Aletaha D, McInnes IB. Rheumatoid arthritis. Lancet. 2016; 388: 2023-38.

2. Picerno V, Ferro F, Adinolfi A, et al. One year in review: the pathogenesis of rheumatoid arthritis. Clin Exp Rheumatol. 2015; 33: 551-8.

3. Prete M, Racanelli V, Digiglio L, et al. Extraarticular manifestations of rheumatoid arthritis: An update. Autoimmun Rev. 2011; 11: 123-31.

4. Pinheiro FA, Souza DC, Sato EI. A Study of Multiple Causes of Death in Rheumatoid Arthritis. J Rheumatol. 2015; 42: 2221-8.

5. Gavrilă BI, Ciofu C, Stoica V. Biomarkers in Rheumatoid Arthritis, what is new? J Med Life. 2016; 9: 144-8.

6. Mc Ardle A, Flatley B, Pennington SR, FitzGerald O. Early biomarkers of joint damage in rheumatoid and psoriatic arthritis. Arthritis Res Ther. 2015; 17: 141.

7. Hensvold AH, Frisell T, Magnusson PK, et al. How well do ACPA discriminate and predict RA in the general population: a study based on 12.590 population-representative Swedish twins. Ann Rheum Dis. 2017; 76: 119-25.

8. Jilani AA, Mackworth-Young CG. The role of citrullinated protein antibodies in predicting erosive disease in rheumatoid arthritis: a systematic literature review and meta-analysis. Int J Rheumatol. 2015; 2015: 728610.

9. Kinloch A, Lundberg K, Wait R, et al. Synovial fluid is a site of citrullination of autoantigens in inflammatory arthritis. Arthritis Rheum. 2008; 58: 2287-95.

10. Snir O, Widhe M, von Spee C, et al. Multiple antibody reactivities to citrullinated antigens in sera from patients with rheumatoid arthritis: association with HLA-DRB1 alleles. Ann Rheum Dis. 2009; 68: 736-43.

11. Snir O, Widhe M, Hermansson M, et al. Antibodies to several citrullinated antigens are enriched in the joints of rheumatoid arthritis patients. Arthritis Rheum. 2010; 62: 44-52.

12. Montes A, Dieguez-Gonzalez R, Perez-Pampin E, et al. Particular association of clinical and genetic features with autoimmunity to citrullinated $\alpha$-enolase in rheumatoid arthritis. Arthritis Rheum. 2011; 63: 654-61.

13. Fisher BA, Plant D, Brode M, et al. Antibodies to citrullinated $\alpha$-enolase peptide 1 and clinical and radiological outcomes in rheumatoid arthritis. Ann Rheum Dis. 2011; 70: 1095-8. 
14. Mahdi H, Fisher BA, Källberg H, et al. Specific interaction between genotype, smoking and autoimmunity to citrullinated alpha-enolase in the etiology of rheumatoid arthritis. Nat Genet. 2009; 41: 1319-24.

15. Arnett FC, Edworthy SM, Bloch DA, et al. The American Rheumatism Association 1987 revised criteria for the classification of rheumatoid arthritis. Arthritis Rheum. 1988; 31: 315-24.

16. Aletaha D, Blüml S. Therapeutic implications of autoantibodies in rheumatoid arthritis. RMD Open 2016; 2: e000009.

17. Schett G, Gravallese E. Bone erosion in rheumatoid arthritis: mechanisms, diagnosis and treatment. Nat Rev Rheumatol. 2012; 8: 656-64.

18. Harre U, Georgess D, Bang H, et al. Induction of osteoclastogenesis and bone loss by human autoantibodies against citrullinated vimentin. J Clin Invest. 2012; 122: 1791-802.

19. Güler-Yüksel M, Allaart CF, Goekoop-Ruiterman YP, et al. Changes in hand and generalised bone mineral density in patients with recent-onset rheumatoid arthritis. Ann Rheum Dis. 2009; 68: 330-6.

20. Vencovský J, Machácek S, Sedová L, et al. Autoantibodies can be prognostic markers of an erosive disease in early rheumatoid arthritis. Ann Rheum Dis. 2003; 62: 427-30.

21. Kleyer A, Finzel S, Rech J, et al. Bone loss before the clinical onset of rheumatoid arthritis in subjects with anticitrullinated protein antibodies. Ann Rheum Dis. 2014; 73: 854-60.
22. Brink M, Verheul MK, Rönnelid J, et al. Anti-carbamylated protein antibodies in the pre-symptomatic phase of rheumatoid arthritis, their relationship with multiple anticitrulline peptide antibodies and association with radiological damage. Arthritis Res Ther. 2015; 17: 25.

23. Kelly CA, Saravanan V, Nisar M, et al. Rheumatoid arthritis-related interstitial lung disease: associations, prognostic factors and physiological and radiological characteristicsa large multicentre UK study. Rheumatology (Oxford). 2014; 53: 1676-82.

24. Alunno A, Caneparo V, Bistoni O, et al. Circulating Interferon-Inducible Protein IFI16 Correlates With Clinical and Serological Features in Rheumatoid Arthritis. Arthritis Care Res (Hoboken). 2016; 68: 440-5.

25. Leech MT, Bartold PM. The association between rheumatoid arthritis and periodontitis. Best Pract Res Clin Rheumatol. 2015; 29: 189-201.

26. Lundberg K, Kinloch A, Fisher BA, et al. Antibodies to citrullinated alpha-enolase peptide 1 are specific for rheumatoid arthritis and cross-react with bacterial enolase. Arthritis Rheum. 2008; 58: 3009-19.

27. Seror R, Le Gall-David S, Bonnaure-Mallet $\mathrm{M}$, et al. Association of Anti-Porphyromonas gingivalis Antibody Titers With Nonsmoking Status in Early Rheumatoid Arthritis: Results From the Prospective French Cohort of Patients With Early Rheumatoid Arthritis. Arthritis Rheumatol. 2015; 67: 1729-37. 